\title{
Scurvy in the developed world
}

\author{
Alexa Smith MD, Gina Di Primio MD, Susan Humphrey-Murto MD MEd
}

See related practice article by Dubé at www.cmaj.ca/lookup/doi/10.1503/cmaj.080505.

Competing interests: None declared.

This article has been peer reviewed.

Correspondence to:

Dr. Alexa Smith,

alexa.smith@dal.ca

CMAJ 2011. DOI:10.1503

/cmaj.091938
A previously well 54-year-old woman was admitted to hospital for investigation of bilateral pain in her legs that prevented her from walking. She had a threeweek history of pain, which started in the knees and progressed to involve the muscles of her lower limbs diffusely. This pain was associated with mild swelling and bruising. She also noted red dots on her legs. Review of systems was positive for a progressive history of fatigue and a 5-lb weight loss over two years.

The patient's medical history included osteoarthritis and osteoporosis. Her medications were alendronate, calcium, vitamin D and acetaminophen. The patient reported allergies to sulfa, penicillin, codeine and nuts. She was a nonsmoker, was employed in a full-time job and denied any social or financial stressors.

On presentation, the patient was mildly tachycardic (heart rate 103 beats/min) with a blood pressure reading of $100 / 67 \mathrm{~mm} \mathrm{Hg}$, but she was otherwise stable. Positive findings included small knee effusions and mild bilateral pitting edema of the lower limbs. Muscles of the lower limbs were very tender to palpation. Nonpalpable petechiae were present on the legs (Figure 1), and extensive ecchymosis could be seen on the posterior thighs and calves (Figure 2).

In hospital, progressive normocytic anemia was noted, with a drop in hemoglobin level from $96 \mathrm{~g} / \mathrm{L}$ to $73 \mathrm{~g} / \mathrm{L}$ (normal 115-155 g/L) over 72 hours. The reticulocyte count was elevated. The leukocyte count was 9.3 (normal

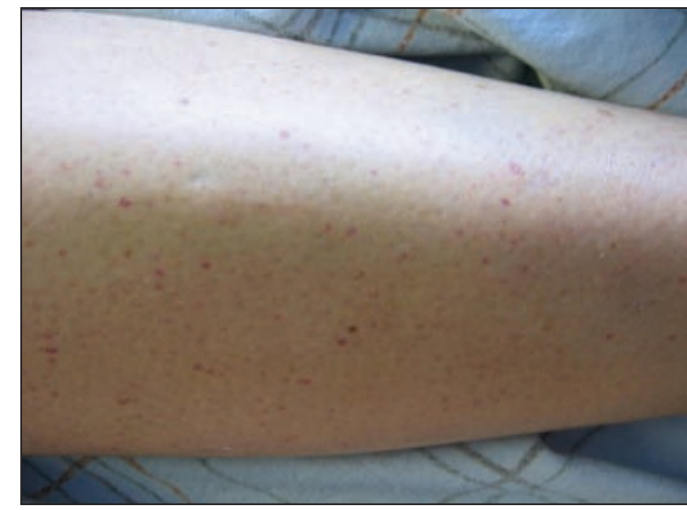

Figure 1: Leg of a 54-year-old woman with bilateral pain in her lower limbs and a diagnosis of scurvy showing purpuric lesions, petechial in appearance. We were unable to note the perifollicular nature of the lesions because the patient had recently shaved. A small-vessel vasculitis could have a similar appearance.

3.0-10.5) $10^{9} / \mathrm{L}$, with a normal differential. Platelets were slightly elevated at 498 (normal 125-400) $10 \%$ L. The erythrocyte sedimentation rate was mildly elevated, and the ferritin level was normal at 312 (normal 24-336) $\mu \mathrm{g} / \mathrm{L}$. Total bilirubin was 75 (normal 24-336) $\mu \mathrm{mol} / \mathrm{L}$, and all other liver enzymes were normal. Haptoglobin, international normalized ratio, creatinine, thyroid-stimulating hormone, creatine kinase, folate and vitamin $\mathrm{B}_{12}$ levels were normal, as was the partial thromboplastin time. Workup for infection, including serology for hepatitis B and $\mathrm{C}$, was negative.

A chest radiograph was normal, as was a computed tomographic scan of the abdomen and pelvis. Further investigations included a normal electromyogram. A skin biopsy of the petechiae showed noninflammatory dermal hemorrhages.

Subcutaneous edema was seen on a plain film of the femur. Magnetic resonance imaging (MRI) of the lower extremities showed mild peripheral increase in $T_{2}$-weighted muscle signal in the distal vastus medialis and lateralis with more prominent bilateral dermal thickening, subcutaneous edema 
and deep fascial edema (Figure 3; Appendix 1, available at www.cmaj.ca/lookup/suppl/doi:10.1503 /cmaj.091938/-/DC1). Similar findings were seen in the gastrocnemius muscles bilaterally (Appendix 2, available at www.cmaj.ca/lookup/suppl /doi:10.1503/cmaj.091938/-/DC1) and also in the calves with prominent subcutaneous and deep fascial edema. The medial gastrocnemius muscles also showed fatty infiltration but no atrophy. Focal enhancing marrow lesions in the right femur were felt to represent islands of red marrow.

Enhanced images did not show areas of muscle necrosis or fluid collections to suggest abscess. The findings of MRI were nonspecific and reported to be in keeping with an inflammatory process.

On further questioning, it became apparent that the patient had been restricting all fruits and most vegetables in an escalating fashion over the past two years because of a perceived allergy. Based on this information, the patient's vitamin $\mathrm{C}$ level was tested, and she was given oral ascorbic acid, $100 \mathrm{mg}$ orally three times per day. Her condition improved substantially within 48 hours. Subsequently, her vitamin $\mathrm{C}$ level was reported to be less than 10 (normal $>25) \mu \mathrm{mol} / \mathrm{L}$, which confirmed the diagnosis of scurvy.

\section{Discussion}

Scurvy is a disease caused by vitamin C deficiency. Vitamin C, also known as ascorbic acid, is necessary in hydroxylation reactions, including procollagen production.

At one time, this disease was common among sailors, soldiers and others without access to fresh fruits and vegetables. The Scottish naval surgeon Sir James Lind first described the effective treatment of scurvy with citrus fruits in $A$ Treatise of the Scurvy in $1753 .{ }^{1}$ With increased awareness for the necessity of fresh fruits and vegetables in one's diet, the rate of scurvy declined through the 18th century.

It has generally been thought that scurvy is an uncommon disease in developed nations. However, a 2008 study found that $25 \%$ of men and $16 \%$ of women from low-income populations in the United Kingdom were deficient in vitamin $\mathrm{C}(<11 \mu \mathrm{mol} / \mathrm{L}){ }^{2}$ A similar study completed in the United States in 2003/04 found that $7.1 \%$ of healthy middle-class participants were vitamin $\mathrm{C}$ deficient $(<11.4 \mu \mathrm{mol} / \mathrm{L})$ and $13.7 \%$ were deplete $(<28 \mu \mathrm{mol} / \mathrm{L}){ }^{3}$ Thus, it is clear that even in industrialized populations with access to fresh food, vitamin $\mathrm{C}$ deficiency is present. Those who are elderly, alcoholics, smokers, mentally ill, and those with low socioeconomic status or restricted diets are particularly at risk for vitamin $\mathrm{C}$ deficiency. ${ }^{4,5}$

\section{Clinical findings}

Patients typically develop clinical findings one to three months after starting a diet void of ascorbic acid. Concentrations below $20 \mu \mathrm{mol} / \mathrm{L}$ may be associated with nonspecific symptoms, such as fatigue, loss of appetite and irritability. Serum concentrations of less than $11.4 \mu \mathrm{mol} / \mathrm{L}$ are considered to indicate substantial vitamin $\mathrm{C}$ deficiency. ${ }^{3}$

Musculoskeletal findings include joint pain, typically of the knees, ankles and wrists; as well as muscle pain and hemarthrosis. ${ }^{6}$ Skin findings can include petechia centred around hair follicles, corkscrew hairs, ecchymosis and hematomas. As in our patient, these changes typically occur first in the legs and buttocks, because these are regions of elevated hydrostatic pressures.

Oral manifestations are inconsistent, but can include hypertrophy and bleeding of gums. ${ }^{7}$ Teeth are required for these oral changes because the inflammation occurs in the supporting tissues of the teeth. It is presumed that teeth provide portals of entry for microbes into the gingiva. ${ }^{8}$

\section{Anemia}

A common laboratory finding in patients with deficiency in vitamin $\mathrm{C}$ is anemia. Vitamin C deficiency can present as an iron-deficiency anemia. It can also present with a normochromicnormocytic pattern. ${ }^{8}$ Most often the anemia can be attributed to acute blood loss resulting from

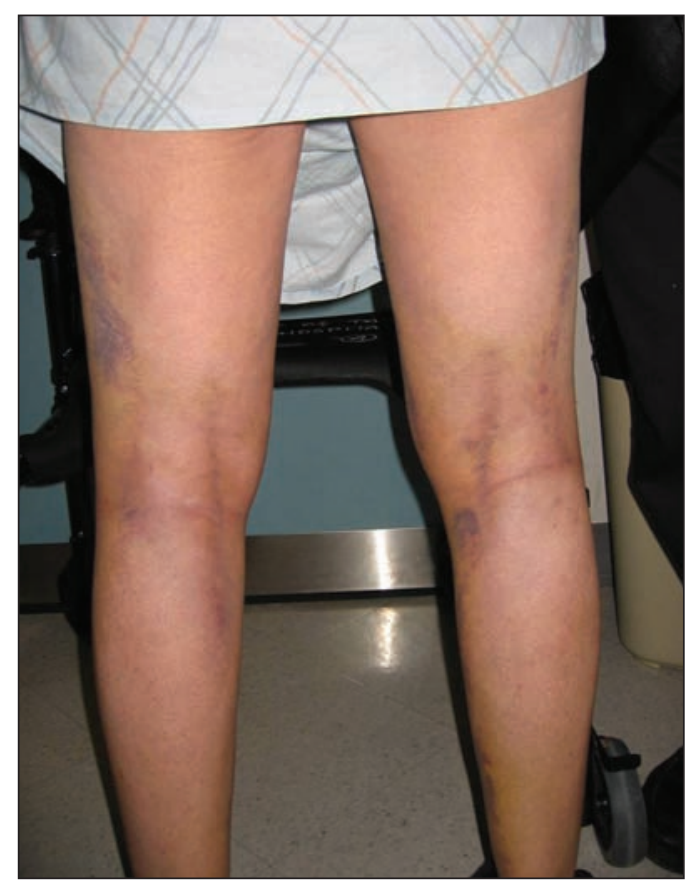

Figure 2: Posterior aspect of thighs and calves of the patient, 48 hours after vitamin C therapy was started, showing ecchymosis in various stages of resorption. 
defects in collagen synthesis. Blood loss can occur from the gastrointestinal tract, joints, muscles and many soft tissue sites. Intravascular hemolysis has also been reported, presumably due to a decreased life span of red cells. ${ }^{8}$

Vitamin $\mathrm{C}$ is important in the absorption and metabolism of many nutrients that affect production of red blood cells. For example, vitamin C aids in the conversion of iron from the ferric to ferrous form, which is required for iron absorption from the gastrointestinal tract. Scurvy can also be associated with folate deficiency. Vitamin $\mathrm{C}$ augments the effect of folate in production of red blood cells, and foods rich in vitamin $\mathrm{C}$ are often the same foods rich in folic acid. ${ }^{9}$

\section{Imaging}

There are few reports of MRI findings associated with scurvy. Because of our patient's musculoskeletal complaints, MRI of the lower extremities was performed. In a previous case report of a 56-year-old man with scurvy, MRI of the leg showed multiple small areas of focal marrow edema. ${ }^{10}$ These $T_{1}$-weighted images were noted to be in the distal metaphyseal region of the femur and proximal tibia, similar in location to our patient's signal changes of the femur and tibia. These findings could represent areas of hemorrhage, infarct or islands of red marrow, all of which are nonspecific findings of scurvy on MRI. ${ }^{10}$ In another report, a 68-year-old woman was admitted to hospital with a similar presentation of progressive lower-extremity pain preventing ambulation. ${ }^{7}$ She was initially diagnosed with cellulitis and underwent an MRI to exlude myositis or osteomyelitis. The imaging showed nonspecific bone marrow edema and osteoporosis. As in our patient, the ultimate diagnosis of scurvy was made through further questioning and clinical examination; however, the MRI helped to rule out other diagnoses. A third case report of a five-year-old child noted diffuse marrow signal changes and subperiosteal fluid. ${ }^{11}$

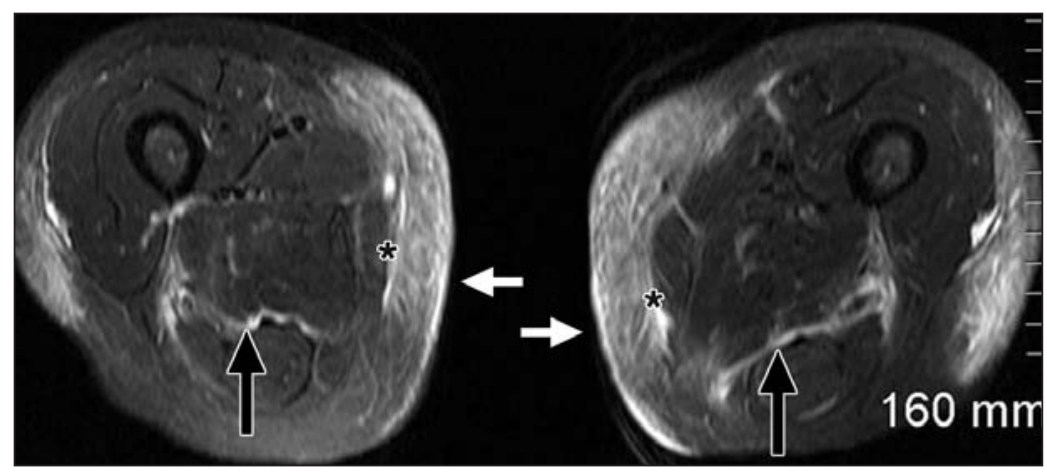

Figure 3: Axial $T_{2}$-weighted fat-saturated magnetic resonance images of the thighs showing dermal thickening and subcutaneous edema (white arrows) with fascial edema underneath (asterisks) and deep fascial edema (black arrows).
This case also reported enhancement on $T_{1}$ weighted images and abnormal signal on $T_{2}$ weighted images of surrounding thigh muscles, particularly of the vastus medialis, which was seen in the imaging of our patient. Initially the subperiosteal changes were thought to represent osteomyelitis, but further investigation confirmed chronic inflammation and hemorrhage, in keeping with scurvy.

On review, our patient's subcutaneous and deep muscle edema, and fluid and fatty infiltration were felt to be secondary to subcutaneous and fascial hemorrhages. These findings are consistent with the conclusion that the patient's normocytic anemia was due to acute blood loss.

\section{Diagnosis}

The diagnosis of scurvy is made clinically, with evidence of inadequate intake of vitamin $\mathrm{C}$ based on a thorough dietary history and characteristic physical findings. Although a decreased ascorbic acid level can be used as an indicator for scurvy, it is not a sensitive test and can be normal in a patient with vitamin $\mathrm{C}$ deficiency. Other laboratory results, such as evidence of anemia, provide support for the diagnosis. Findings on imaging are nonspecific and will not lead to the diagnosis, but may serve to rule out other potential etiologies, particularly in those who present with musculoskeletal complaints. A practical clinical indicator for scurvy is a rapid response to oral vitamin $\mathrm{C} .{ }^{9}$

\section{Treatment}

If vitamin $\mathrm{C}$ deficiency is suspected based on a history of poor nutrition or physical examination, oral vitamin $\mathrm{C}$ should be started immediately. Symptoms of scurvy have improved with varying doses of ascorbic acid, and one review found as little as $6.5 \mathrm{mg}$ daily improved symptoms. ${ }^{8}$ However, expert opinion recommends oral supplementation of $300 \mathrm{mg}$ daily in divided doses of ascorbic acid for at least one month or until body stores are replenished, indicated by serum levels. ${ }^{9}$ Patients' subjective complaints can improve within 24 hours of starting treatment. ${ }^{8}$ As with our patient, objective findings, such as ecchymosis resorption, can begin to improve within only 48 hours of treatment. After serum levels are replenished, patients should ensure they are meeting the estimated daily requirement of vitamin C. In US recommendations, the estimated average requirement for women is $60 \mathrm{mg} / \mathrm{d}$ for nonsmokers and $95 \mathrm{mg} / \mathrm{d}$ for smokers $(75 \mathrm{mg} / \mathrm{d}$ and $110 \mathrm{mg} / \mathrm{d}$, respectively, in male populations). ${ }^{3}$ The recommended dietary allowance for vitamin $\mathrm{C}$ in Canada is $75 \mathrm{mg} / \mathrm{d}$ in women and $90 \mathrm{mg} / \mathrm{d}$ in men; the daily allowance varies with age and sex, and in pregnancy or breastfeeding. ${ }^{12}$ 


\section{References}

1. Lind J. A treatise of the scurvy. In three parts. Containing an inquiry into the nature, causes and cure, of that disease. Together with a critical and chronological view of what has been published on the subject. Edinburgh (UK): Sands, Murray and Cochran for A. Kincaid and A. Donaldson; 1753.

2. Mosdøl A, Erens B, Brunner EJ. Estimated prevalence and predictors of vitamin C deficiency within UK's low-income population. J Public Health (Oxf) 2008;30:456-60.

3. Schleicher RL, Carroll MD, Ford ES, et al. Serum vitamin C and the prevalence of vitamin C deficiency in the United States: 2003-2004 National Health and Nutrition Examination Survey (NHANES). Am J Clin Nutr 2009;90:1252-63.

4. Velandia B, Centor RM, McConnell V, et al. Scurvy is still present in developed countries. J Gen Intern Med 2008;23:1281-4.

5. Hampl JS, Taylor CA, Johnston CS. Vitamin C deficiency and depletion in the United States: The Third National Health and Nutrition Examination Survey, 1988 to 1994. Am J Public Health 2004;94:870-5.

6. Fain O. Musculoskeletal manifestations of scurvy. Joint Bone Spine 2005;72:124-8.

7. Patrozou E, Opal S. Scurvy masquerading as infectious cellulites. IMJ 2008;38:452

8. Hirschmann JV, Raugi GJ. Adult scurvy. J Am Acad Dermatol 1999;41:895-906

9. Popovich D, McAlhany A, Adewumi AO, et al. Scurvy: forgotten but definitely not gone. J Pediatr Health Care 2009;23:405-15.

10. Karthiga S, Dubey S, Garber S, et al. Scurvy: MRI appearances. Rheumatology 2008;47:1109.

11. Choi SW, Park SW, Kwon YS, et al. MR imaging in a child with scurvy: a case report. Korean J Radiol 2007;8:443-7.

12. Vitamin $C$ monograph. Ottawa (ON): Health Canada; 2007. Available: www.hc-sc.gc.ca/dhp-mps/prodnatur/applications /licen-prod/monograph/mono_vitamin_c-eng.php (accessed 2011 Feb. 7)
Affiliations: From the Department of Medicine, Divisions of General Internal Medicine (Smith) and Rheumatology (Humphrey-Murto); and the Department of Diagnositic Imaging (Di Primio), The Ottawa Hospital, University of Ottawa, Ottawa, Ont

Contributors: Alexa Smith drafted the manuscript, which Gina Di Primio and Susan Humphrey-Murto revised. All authors approved the final version submitted for publication.

The section Cases presents brief case reports that convey clear, practical lessons. Preference is given to common presentations of important rare conditions, and important unusual presentations of common problems. Articles start with a case presentation (500 words maximum), and a discussion of the underlying condition follows (1000 words maximum). Generally, up to five references are permitted and visual elements (e.g., tables of the differential diagnosis, clinical features or diagnostic approach) are encouraged. Written consent from patients for publication of their story is a necessity and should accompany submissions. See information for authors at www.cmaj.ca. 